\title{
Long-Lasting Effects of a PEGylated Mutant Cocaine Esterase (CocE) on the Reinforcing and Discriminative Stimulus Effects of Cocaine in Rats
}

\author{
Gregory T Collins*, 1,2, Diwahar Narasimhan', Alyssa R Cunningham', Matthew E Zaks', Joseph Nichols', \\ Mei-Chuan Ko', Roger K Sunahara' and James H Woods' \\ 'Department of Pharmacology, University of Michigan Medical School, Ann Arbor, MI, USA
}

\begin{abstract}
Recent mutagenesis studies have identified a mutant G4C/S I0C/TI72R/GI73Q cocaine esterase (CCRQ CocE) with an in vitro duration of action of $>40$ days. Although the in vivo duration of CCRQ CocE's action was $<24 \mathrm{~h}$, modification of this enzyme with polyethylene glycol (PEG) polymers resulted in a CocE (PEG-CCRQ CocE) capable of preventing cocaine-induced lethality for up to $72 \mathrm{~h}$. The current studies were aimed at providing a detailed characterization of the effectiveness, selectivity, and duration of PEG-CCRQ CocE's actions in cocaine self-administration and discrimination assays in rats. Pretreatment with PEG-CCRQ CocE produced dose-dependent rightward shifts in the dose-response curves for cocaine self-administration and discrimination, with the highest dose of PEG-CCRQ CocE capable of producing an initial shift of cocaine's reinforcing and interoceptive effects of $>30$-fold to the right, with significant inhibition of these effects observed for up to $72 \mathrm{~h}$. Although PEG-CCRQ CocE also produced slight reductions in the rates of methylphenidate- and foodreinforced responding, these effects were short-lived, lasting $<24 \mathrm{~h}$. Finally, when taken together with the finding that PEG-CCRQ CocE failed to alter the cocaine-like interoceptive effects of either methylphenidate or d-amphetamine, these results suggest that PEG-CCRQ CocE possesses a high degree of pharmacologic specificity for cocaine and a prolonged in vivo duration of action. In conclusion, these studies provide strong evidence to support the further development of long-lasting, highly efficient CocEs, such as PEG-CCRQ CocE, as a potential therapeutic option for the treatment of cocaine abuse in humans.
\end{abstract}

Neuropsychopharmacology (2012) 37, 1092-1 I03; doi:I0.1038/npp.201।.226; published online I2 October 20 I I

Keywords: cocaine esterase; PEG-CCRQ CocE; cocaine; methlyphenidate; self-administration; drug discrimination

\section{INTRODUCTION}

Cocaine abuse remains a significant worldwide public health problem, with an estimated 20 million individuals using cocaine during the 2009 calendar year (UNODC, 2010). Despite longstanding efforts to identify small molecules capable of selectively inhibiting the reinforcing effects of cocaine (eg, Dackis and O'Brien, 2003; Grabowski et al, 2004; Mello, 1990; Platt et al, 2002; Roberts and Brebner, 2000; Tanda et al, 2009; Vocci et al, 2005), there are currently no approved pharmacotherapies for the treatment of cocaine abuse. Recently, significant efforts have been made toward developing protein-based pharmacotherapies as an alternative approach to treating cocaine abuse with the goal of reducing the amount of cocaine that

*Correspondence: Dr GT Collins, Alcohol and Drug Abuse Research Center, McLean Hospital, Harvard Medical School, II5 Mill Street, Belmont, MA 02478, USA, Tel: + | 617855 26I I, Fax: 734764 7l I8, E-mail: gcollins@mclean.harvard.edu

${ }^{2}$ Current address: Alcohol and Drug Abuse Research Center, McLean Hospital, Harvard Medical School, Belmont, MA, USA

Received 26 July 2011; revised 18 August 2011; accepted 18 August 2011 is able to reach its central sites of action by altering the pharmacodynamic and/or pharmacokinetic properties of cocaine. Cocaine-specific antibodies achieve this by sequestering cocaine in the periphery (eg, Fox et al, 1996; Martell et al, 2005), whereas cocaine-specific enzymes and catalytic antibodies reduce the central effects of cocaine by enhancing the metabolism and clearance of cocaine, thus reducing the circulating concentrations of cocaine within both the central and peripheral nervous systems (eg, Landry and Yang, 1997; Turner et al, 2002).

Although cocaine-specific antibodies have been shown to reduce the reinforcing and/or subjective effects of cocaine in both preclinical (Carrera et al, 2000; Fox et al, 1996; Kantak et al, 2000), and clinical studies (Haney et al, 2010; Martell et al, 2005), many of these studies also suggest that the protective effects of cocaine-specific antibodies are easily surmounted by increasing the rate and/or amount of cocaine intake. One approach to circumvent these stoichiometric limitations has been to develop catalytic antibodies, such as mAb 15A10, which not only sequester cocaine in the periphery, but also catalyze its breakdown (Landry et al, 1993). Although this approach has been shown to selectively decrease cocaine self-administration in rats (Baird et al, 
2000; Mets et al, 1998), its utility has been limited by the relatively poor efficiency with which $\mathrm{mAb} 15 \mathrm{~A} 10$ metabolizes cocaine (Kcat/Km $\sim 26$-fold lower than butyrylcholinesterase (BChE)). Nevertheless, together with the demonstration that exogenous $\mathrm{BChE}$ is capable of reducing the toxic effects of cocaine (Lynch et al, 1997), these experiments provided the theoretical basis for the development of highly efficient cocaine-specific enzymes as pharmacotherapies for cocaine toxicity and abuse (eg, Zhan et al, 2003).

Cocaine is naturally metabolized by $\mathrm{BChE}$ to the inactive metabolites ecgonine methyl ester and benzoic acid, with elimination half-lives for cocaine of $\sim 26 \mathrm{~min}$ in rats and $\sim 45 \mathrm{~min}$ in non-human and human primates (Carmona et al, 2005; Mello et al, 2002; Mendelson et al, 1999). In an attempt to improve upon BChE's catalytic efficiency, Zhan and colleagues have used site-directed mutagenesis to create mutant BChEs capable of hydrolyzing cocaine $\sim 450-2000$ times more efficiently than native BChE (Pan et al, 2005; Zheng et al, 2008). These mutant BChEs have shown promising results when evaluated in rodents, effectively reducing the cardiovascular, lethal, and response-reinstating effects of cocaine (Brimijoin et al, 2008; Xue et al, 2010; Zheng et al, 2008). In addition, an albumin-fused mutant $\mathrm{BChE}$ (Albu-CocH) has been shown to decrease progressive ratio responding for cocaine (Carroll et al, 2011), suggesting that it is also capable of reducing the reinforcing effectiveness of cocaine.

In addition to mutant $\mathrm{BChEs}$, a highly efficient (Kcat/Km $\sim 800$-fold greater than BChE; Larsen et al, 2002; Turner et al, 2002), bacterial cocaine esterase (CocE) has been isolated from a strain of Rhodococcus growing in the soil around coca plants (Bresler et al, 2000) and extensively evaluated as a possible treatment for cocaine toxicity and abuse. Although the wild-type (wt) form of CocE is capable of dose dependently protecting mice and rats against the cardiovascular, convulsant, and lethal effects of cocaine, it is rapidly inactivated at body temperature resulting in an in vivo half-life of $\sim 15 \mathrm{~min}$ (Cooper et al, 2006; Jutkiewicz et al, 2009; Ko et al, 2007, 2009; Wood et al, 2010). Sitedirected mutagenesis studies aimed at improving the thermostability of CocE have identified an equally efficient mutant CocE (T172R/G173Q CocE, RQ CocE, DM CocE) with an in vivo half-life of $\sim 4.5 \mathrm{~h}$ in mice (Gao et al, 2009; Narasimhan et al, 2010), and a high degree of pharmacologic specificity (Brim et al, 2011). In addition to dose dependently inhibiting the cardiovascular, convulsant, lethal, and reinforcing effects of cocaine in rats (Collins et al, 2009, 2011b), DM CocE has also been shown to effectively reverse the cardiovascular effects associated with large intravenous (IV) doses of cocaine in rhesus monkeys (Collins et al, 2011a). While these findings suggest that DM CocE should provide an effective treatment option for acute cocaine toxicity in humans, its in vivo duration of action is likely too short to provide a realistic option for the treatment of cocaine abuse.

Recently, substitution of cysteine residues at the Gly4 and Ser10 positions of RQ CocE has been shown to result in a mutant G4C/S10C/T172R/G173Q CocE (CCRQ CocE) with an in vitro half-life of $>40$ days at $37^{\circ} \mathrm{C}$. In rodents, however, the duration of CCRQ CocE's actions was $<24 \mathrm{~h}$. Modification of biologic entities with polyethylene glycol
(PEG) moieties has been shown to lengthen in vivo residence times by imparting stealth properties (Caliceti and Veronese, 2003). The addition of two $40 \mathrm{kDa}$ branched PEG moieties (one per monomer) to CCRQ CocE (PEGCCRQ CocE) dramatically increased its in vivo duration of action in rodents, with a $32.0-\mathrm{mg} / \mathrm{kg}$ dose of PEG-CCRQ CocE capable of reducing the reinforcing effects of $0.1 \mathrm{mg} /$ $\mathrm{kg} / \mathrm{inj}$ cocaine for up to $96 \mathrm{~h}$, and the lethal effects of $180.0 \mathrm{mg} / \mathrm{kg}$ cocaine for up to $72 \mathrm{~h}$ (Narasimhan et al, 2011). Briefly, the current studies were aimed at extending these findings by providing a detailed characterization of the effectiveness, selectivity, and duration of PEG-CCRQ CocE's actions in cocaine self-administration and discrimination assays in rats. Accordingly, the effects of three doses of PEG-CCRQ CocE were evaluated against at least a 100-fold range of cocaine doses in self-administration and drug discrimination procedures, with the daily assessment of cocaine dose-response curves used to determine the in vivo duration of PEG-CCRQ CocE's actions. In addition, methylphenidate (self-administration and drug discrimination) and d-amphetamine (drug discrimination only) were also used to evaluate PEG-CCRQ CocE's pharmacologic selectivity, whereas rates of food-reinforced responding were used to evaluate the behavioral selectivity of PEGCCRQ CocE's effects.

\section{METHODS}

\section{Subjects}

Male Sprague-Dawley rats (325-350 g) were obtained from Harlan (Indianapolis, IN) and maintained in a temperature and humidity controlled environment, on a 12-h dark/light cycle with lights on at $0700 \mathrm{~h}$. All rats were singly housed with free access to tap water and $\sim 20 \mathrm{~g}$ of food per day. All experimental procedures were approved by the University of Michigan Committee on the Use and Care of Animals, and performed in accordance with the Guide for the Care and Use of Laboratory Animals as adopted and promulgated by the National Institutes of Health.

\section{Surgery}

Rats were prepared with chronic indwelling catheters in the left femoral vein under ketamine:xylazine $(90: 10 \mathrm{mg} / \mathrm{kg}$; intraperitoneal (IP)) anesthesia. Catheters were passed under the skin and attached to stainless steel tubing that exited through a metal tether button that was sutured to the muscle between the scapulae. A 5-7-day recovery period was provided before experimentation. Catheters were flushed daily with $0.2 \mathrm{ml}$ of heparinized saline $(100 \mathrm{U} / \mathrm{ml})$ before the start, and after the completion of operant sessions.

\section{Apparatus}

All experimental sessions were conducted in operant conditioning chambers $(30.5 \mathrm{~cm} \mathrm{~W} \times 24 \mathrm{~cm} \mathrm{D} \times 21 \mathrm{~cm} \mathrm{H}$; Med Associates, St Albans, VT) placed inside sound attenuating cubicles. For self-administration studies, each chamber was equipped with two nosepoke devices (ENV114BM; Med Associates) positioned $6 \mathrm{~cm}$ above the stainless 
steel grid floor and illuminated with a yellow stimulus light. Each chamber was also equipped a red, yellow, and green LED stimulus complex located above each nosepoke, and a white house light located on the top of the opposite wall. A syringe driver (PMH-100-20; Med Associates) delivered solutions through Tygon tubing connected to a fluid swivel (Instech Laboratories, Plymouth Meeting, PA) and spring tether, which was held in place by a counterbalanced arm. For discrimination and sucrose reinforcement studies, chambers were equipped with two retractable levers, located $6 \mathrm{~cm}$ above the floor and on either side of a pellet dispenser (ENV-203M; Med Associates) which delivered $45 \mathrm{mg}$ sucrose pellets (Bio-Serv, Frenchtown, NJ) into an external pellet cup. In these chambers, a LED stimulus complex was located above each of the levers as well as the pellet cup.

\section{Self-Administration Studies}

Acquisition of responding for IV drugs. Rats were initially trained to nosepoke for injections of either $0.32 \mathrm{mg} / \mathrm{kg}$ cocaine or $0.1 \mathrm{mg} / \mathrm{kg}$ methylphenidate $(n=6 / \mathrm{drug})$ during daily, 60 min sessions under a fixed ratio (FR) 1 schedule of reinforcement. Illumination of the yellow stimulus light inside the left nosepoke signaled drug availability, with subsequent responses on this nosepoke resulting in drug injection $(320 \mu \mathrm{l} / \mathrm{kg}$ delivered over $\sim 1 \mathrm{~s})$. Injections were accompanied by the illumination of the red, yellow, and green LEDs above the left nosepoke, and followed by a 5-s time out (TO) during which the house light was illuminated and responses were recorded but had no scheduled consequence. Ratio requirements were gradually increased $(1,2,3$, and 5) until rats were responding under an FR5TO5 schedule of reinforcement. Upon stabilization of responding, defined as three consecutive sessions with less than a $20 \%$ variation and no increasing or decreasing trend in responding, rats were transferred to a multi-component, 5dose procedure. Under this procedure, increasing doses of cocaine $(0,0.032,0.1,0.32$, and $1.0 \mathrm{mg} / \mathrm{kg} / \mathrm{inj})$ or methylphenidate $(0,0.01,0.032,0.1$, and $0.32 \mathrm{mg} / \mathrm{kg} / \mathrm{inj})$ were available during five sequential $25 \mathrm{~min}$ components (eg, Barrett et al, 2004; Hiranita et al, 2009). Components were initiated by the non-contingent delivery of the unit dose of the drug available for responding, and separated by a 2-min inter-component interval (ICI) during which time the house light was illuminated and responding had no scheduled consequence. During this phase of the experiment, the concentrations of cocaine $(1.0 \mathrm{mg} / \mathrm{ml})$ and methylphenidate $(0.32 \mathrm{mg} / \mathrm{ml})$ in the syringe were constant, with the different unit doses delivered by altering the injection duration (adjusted for body weight). For example, the volumes and injection durations for a $320-\mathrm{g}$ rat were as follows: $0.0 \mathrm{mg} /$ $\mathrm{kg} / \mathrm{inj}=0 \mu \mathrm{l}$ over $0 \mathrm{~s}$ (stimuli only); $0.032 \mathrm{mg} / \mathrm{kg} / \mathrm{inj}=10 \mu \mathrm{l}$ over $0.1 \mathrm{~s} ; \quad 0.1 \mathrm{mg} / \mathrm{kg} / \mathrm{inj}=32 \mu \mathrm{l}$ over $0.3 \mathrm{~s} ; 0.32 \mathrm{mg} / \mathrm{kg} /$ inj $=100 \mu \mathrm{l}$ over $1 \mathrm{~s}$; and $1.0 \mathrm{mg} / \mathrm{kg} / \mathrm{inj}=320 \mu \mathrm{l}$ over $3 \mathrm{~s}$. Rats were maintained on this schedule for the remainder of the experiment, with stability defined as three consecutive sessions with $<20 \%$ difference in responding during each of the five components.

Effects of PEG-CCRQ CocE on the IV self-administration of cocaine and methylphenidate. Upon the acquisition of stable responding for cocaine or methylphenidate under the 5-dose schedule, rats were exposed to a single session saline substitution to determine the effects of removing the reinforcer on the maintenance of responding. Maintenance doses of cocaine $(0.032-1.0 \mathrm{mg} / \mathrm{kg} / \mathrm{inj})$, or methylphenidate (0.01-0.32 $\mathrm{mg} / \mathrm{kg} / \mathrm{inj})$ were reintroduced on the following day. In order to evaluate the capacity of PEG-CCRQ CocE to shift the dose-response curve for cocaine-maintained responding, pretreatments with PEG-CCRQ CocE were administered before sessions in which a $3.2-\mathrm{mg} / \mathrm{ml}$ dose of cocaine was loaded into the syringe, resulting in larger unit doses of cocaine being available for responding (0.1-3.2 mg/ $\mathrm{kg} / \mathrm{inj}$ ). This range of cocaine doses was available during the session that occurred 0 and $24 \mathrm{~h}$ after pretreatment with $3.2 \mathrm{mg} / \mathrm{kg}$ PEG-CCRQ CocE, 0,24 , and $48 \mathrm{~h}$ after pretreatment with 10.0 PEG-CCRQ CocE, and 0, 24, 48, and $72 \mathrm{~h}$ after pretreatment with $32.0 \mathrm{mg} / \mathrm{kg}$ PEG-CCRQ CocE. Subsequently, the syringe was filled with $1.0 \mathrm{mg} / \mathrm{ml}$ cocaine, and rats were once again allowed to respond for the maintenance doses of cocaine $(0.032-1.0 \mathrm{mg} / \mathrm{kg} / \mathrm{inj})$. All rats received all doses of PEG-CCRQ CocE, with the doses presented in random order, and separated by at least 7 days to allow for drug washout and the reacquisition of stable responding under maintenance conditions.

The effects of PEG-CCRQ CocE (10.0 and $32.0 \mathrm{mg} / \mathrm{kg}$; IV) on responding maintained by methylphenidate were also evaluated, with pretreatments administered before sessions in which the maintenance doses of methylphenidate (0.01$0.32 \mathrm{mg} / \mathrm{kg} / \mathrm{inj}$ ) were available for responding. The order of PEG-CCRQ CocE doses was counterbalanced across rats and separated by at least seven sessions to allow for drug washout and the reacquisition of stable responding under the maintenance conditions.

Acquisition of responding for sucrose pellets. Rats were initially trained to respond for $45 \mathrm{mg}$ sucrose pellets during daily, $60 \mathrm{~min}$ sessions under an FR1TO5 schedule of reinforcement identical to that described for IV selfadministration, and the ratio requirements were gradually increased until rats were stably responding under an FR5TO5. Subsequently, sucrose pellets were made available under an FR5TO5 schedule of reinforcement during five sequential 25 min components, each separated by a 2 -min ICI signaled by illumination of the house light. Food pellets were unavailable during the first component; instead, ratio completion resulted in the stimuli that normally accompanied pellet delivery and a 5-s TO. Subsequent components were signaled by the non-contingent delivery of a sucrose pellet, with an additional 29 pellets available for responding. After all 29 pellets for an individual component were earned, the house light was illuminated and rats spent the remainder of the $25-\mathrm{min}$ component in TO. The next component began after the TO and 2 min ICI had elapsed.

Effects of PEG-CCRQ CocE on responding for sucrose pellets. Upon stabilization of responding under maintenance conditions, rats were pretreated PEG-CCRQ CocE (10.0 and $32.0 \mathrm{mg} / \mathrm{kg}$; IV) or phosphate-buffered saline (PBS; vehicle) immediately before the start of sessions. These sessions were identical to maintenance sessions with the exception that rats were briefly removed from the chamber during the 2-min ICI and injected with saline (IP). In order to confirm PEG-CCRQ CocE's activity, a second 
test session was conducted $48 \mathrm{~h}$ later during which cumulative doses of cocaine $(1.0,3.2,10.0$, and $32.0 \mathrm{mg} /$ $\mathrm{kg}$; IP) were administered during the 2-min ICI before components 1 through 4, respectively. No injections were given before the start of the extinction (EXT) component.

\section{Drug Discrimination Studies}

Discrimination training. Rats were initially trained to respond under an FR10TO5 for sucrose pellets on both the right and left levers during alternating components (ie, 10 pellets on the right and 10 pellets on the left) with a maximum of 40 pellets per session. Once rats consistently earned all 40 pellets, they were trained to discriminate $10.0 \mathrm{mg} / \mathrm{kg}$; IP cocaine from saline using a single-alternation, two-lever discrimination procedure, with the position (right/left) of the cocaine-appropriate lever counterbalanced across rats. Following cocaine or saline administration, rats were placed into an operant chamber, illuminated by the house light, for a 10-min pretreatment period. The start of the session was signaled by the EXT of the house light, insertion of the levers, and the illumination of the yellow LEDs above each of the levers. Ratio completion (FR10) on the injection-appropriate lever resulted in sucrose pellet delivery followed by a 5-s TO during which the yellow LEDs above the levers were extinguished and the red, yellow, and green LEDs above the pellet tray were illuminated. Responding on the alternate lever was recorded, but had no scheduled consequence. Sessions terminated after 10 reinforcers or $10 \mathrm{~min}$ had elapsed, whichever came first, at which point the levers were retracted, all LEDs were extinguished, and the house light was illuminated. Upon acquisition of the discrimination, defined as three consecutive sessions with $>80 \%$ injection-appropriate responding during the first ratio and entire session, the number of components was gradually increased to 5, with each component identical to the initial discrimination training session. Daily sessions comprising 1-5 components (randomized across days), with each component preceded by the administration of either saline or $10.0 \mathrm{mg} / \mathrm{kg}$; IP cocaine. Although saline could be administered before any component, the administration of cocaine always occurred before the terminal component of the session. Thus, if cocaine was administered before the first component, the session was one component long. Training continued until rats were allocating at least $80 \%$ of their responding on the injection appropriate during the first ratio of each component, as well as for components as a whole.

Discrimination testing. Once rats met training criteria, two types of test were performed: substitution tests and pretreatment tests. During test sessions, completion of a ratio on either lever resulted in the delivery of a sucrose pellet, and the resetting of the ratio requirements on both levers. Sessions comprising 3-5 components, and terminated after rats allocated at least $80 \%$ of their total responding on the cocaine-appropriate lever, or if rats failed to complete a ratio on either lever during the component, which ever occurred first.

Substitution tests. The following drugs were evaluated using a cumulative dosing procedure: cocaine $(0.32,1.0,3.2$, and $10.0 \mathrm{mg} / \mathrm{kg} ; \mathrm{IP})$, methylphenidate $(0.32,1.0,3.2,10.0$, and $18.0 \mathrm{mg} / \mathrm{kg}$; IP), d-amphetamine $(0.032,0.1,0.32$, and $1.0 \mathrm{mg} / \mathrm{kg}$; IP), and ketamine (1.0, 3.2, 10.0, 18.0, and $32.0 \mathrm{mg} / \mathrm{kg}$; IP). Most drugs were administered as $10 \mathrm{~min}$ pretreatments.

Effects of PEG-CCRQ CocE on the discriminative stimulus effects of cocaine and cocaine-like drugs. Pretreatments with PEG-CCRQ CocE (3.2, 10.0, and $32.0 \mathrm{mg} / \mathrm{kg}$; IV) or PBS occurred $1 \mathrm{~min}$ before the first injection of the session, with cumulative doses of $0.32,1.0,3.2$, and $10.0 \mathrm{mg} / \mathrm{kg}$; IP cocaine tested in PBS-treated rats, and the cumulative doses of 10.0, 32.0, 56.0, 100.0, and $180.0 \mathrm{mg} / \mathrm{kg}$; IP cocaine evaluated after pretreatment with PEG-CCRQ CocE. These doses of cocaine were evaluated daily until rats allocated at least $80 \%$ of their responding on the cocaine-appropriate lever following the $10.0-\mathrm{mg} / \mathrm{kg}$ training dose of cocaine. Test sessions were identical to those described above, with the exception that $>80 \%$ cocaine-appropriate responding or failure to complete a ratio would terminate sessions after any of the five components (ie, sessions comprising 1-5 components).

A second set of pretreatment tests were conducted to evaluate the effects of a $32.0-\mathrm{mg} / \mathrm{kg}$; IV dose of PEG-CCRQ CocE against methylphenidate, d-amphetamine, and cocaine over 3 successive days. Substitution tests with methylphenidate $(0.32,1.0,3.2,10.0$, and $18.0 \mathrm{mg} / \mathrm{kg} ; \mathrm{IP})$ and d-amphetamine $(0.032,0.1,0.32$, and $1.0 \mathrm{mg} / \mathrm{kg} ; \mathrm{IP})$ were initiated either $1 \mathrm{~min}$ or $24 \mathrm{~h}$ after PEG-CCRQ CocE administration, with the order counterbalanced across rats. Cocaine $(0.32,1.0,3.2,10.0$, and $18.0 \mathrm{mg} / \mathrm{kg}$; IP) was always administered during the third session, $48 \mathrm{~h}$ after PEG-CCRQ CocE administration.

\section{Drugs}

Cocaine, methylphenidate, and d-amphetamine were obtained from the National Institute on Drug Abuse (Bethesda, MD). Ketamine was purchased from Henry Schein (Denver, PA). All drugs were dissolved in physiologic saline, and administered IV for self-administration studies, and IP for drug discrimination studies. PEG-CCRQ CocE was prepared and purified as previously described (Narasimhan et al, 2011), and administered IV on a $\mathrm{mg} / \mathrm{kg}$ basis in a volume of no $>10 \mathrm{ml} / \mathrm{kg}$ immediately before the beginning of operant sessions.

\section{Data analysis}

For self-administration studies, data are presented as the mean \pm the standard error of the mean (SEM), $n=6$, number of injections earned (IV drug self-administration), or ratios completed (food reinforcement) per $25 \mathrm{~min}$ component (GraphPad Prism; GraphPad Software, San Diego, CA). For food reinforcement studies, data are also presented as the mean $\pm S E M$ of the overall rate of responding (responses per second) during the active portion of each component. Significant effects of PEGCCRQ CocE on the number of injections earned, ratios completed, and rates of responding were determined by two-way ANOVA with post hoc Bonferroni tests (GraphPad 
Prism). For drug discrimination studies, data are presented as the mean \pm SEM, $n=5$, of the percent of overall responding that occurred on the cocaine-appropriate lever, and the overall response rate (responses per second) during the active portion of each component. Linear regression analyses (GraphPad Prism) were used to determine if there was a significant correlation between dose and percent cocaine-appropriated responding, with a full generalization to the discriminative stimulus effects of cocaine defined as a significant non-zero slope and at least $80 \%$ of the overall responding occurring on the cocaine-appropriate lever during any component. Dose ratios (dose required to produce $50 \%$ maximal effect $\left.\left(\mathrm{ED}_{50}\right) \mathrm{PEG}-\mathrm{CCRQ} / \mathrm{ED}_{50} \mathrm{PBS}\right)$ were determined for each rat, with the average $(95 \%$ confidence interval (CI)) dose ratio used to describe the degree to which PEG-CCRQ CocE shifted the dose-response curves for substitute drugs, with a significant shift defined as a $95 \% \mathrm{CI}$ not inclusive of 1.0 .

\section{RESULTS}

Baseline dose-response curves for responding maintained by increasing doses of cocaine $(0.032-1.0 \mathrm{mg} / \mathrm{kg} / \mathrm{inj}$ or $0.1-$ $3.2 \mathrm{mg} / \mathrm{kg} / \mathrm{inj}$ ) and methylphenidate $(0.01-0.32 \mathrm{mg} / \mathrm{kg} / \mathrm{inj})$ are shown in Figure 1. Both drugs maintained responding in a dose-dependent manner (cocaine $0.0-1.0 \mathrm{mg} / \mathrm{kg} / \mathrm{inj}$ : $\mathrm{F}(4,20)=$ 82.3; $p<0.001 ;$ cocaine $0.0-3.2 \mathrm{mg} / \mathrm{kg} / \mathrm{inj}: \mathrm{F}(4,20)=56.0$; $p<0.001$; methylphenidate: $\mathrm{F}(4,20)=31.0 ; p<0.001)$ with inverted U-shaped dose-response curves, and peak levels of responding observed at doses of 0.032 and $0.1 \mathrm{mg} / \mathrm{kg} / \mathrm{inj}$ for methylphenidate and cocaine, respectively. Importantly, there were no significant differences in the numbers of cocaine injections $(0.1,0.32$, or $1.0 \mathrm{mg} / \mathrm{kg} / \mathrm{inj})$ earned when the maintenance range of cocaine doses $(0.032-1.0 \mathrm{mg} / \mathrm{kg} / \mathrm{inj})$, or a higher range of cocaine doses $(0.1-3.2 \mathrm{mg} / \mathrm{kg} / \mathrm{inj})$ were available for injection. In addition, although responding

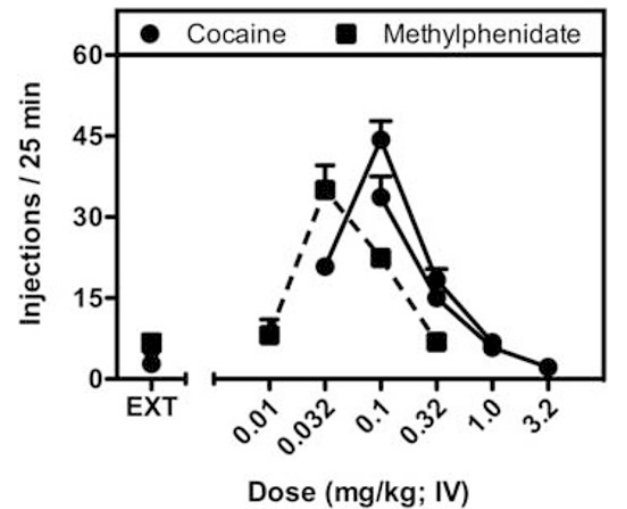

Figure I Dose-response curves for responding maintained during five sequential 25 min components in which increasing doses of cocaine (filled circles) or methylphenidate (filled squares) were available for injection under an FR5TO5 schedule of reinforcement. Cocaine was available over one of two dose ranges $(0.0,0.032,0.1,0.32$, and $1.0 \mathrm{mg} / \mathrm{kg} / \mathrm{inj}$ or $0.0,0.1$, $0.32,1.0$, and $3.2 \mathrm{mg} / \mathrm{kg} / \mathrm{inj})$, and methylphenidate was available over one range of doses $(0.0,0.01,0.032,0.1$, and $0.32 \mathrm{mg} / \mathrm{kg} / \mathrm{inj})$. Data represent the mean \pm the standard error of the mean (SEM) number of injections $(n=6)$ earned during each 25 min component. Points above extinction (EXT) refer to the number of completed ratios that resulted in presentation of stimuli associated with injections, but no injection. occurred at significantly lower rates when ratio completion resulted in saline injections $(\mathrm{F}(1,25)=35.7 ; p<0.001)$, baseline levels of responding were recovered during the first session after the reintroduction of cocaine (Figure 2; top left panel).

When administered immediately before the start of an operant session in which rats had access to cocaine injections, pretreatment with PEG-CCRQ CocE dose dependently $(\mathrm{F}(3,75)=4.8 ; p<0.001)$ affected the capacity of cocaine to maintain responding, with doses of 3.2 and $10.0 \mathrm{mg} / \mathrm{kg}$ PEG-CCRQ CocE shifting the dose-response curve for IV cocaine self-administration $\sim 10$-fold and 30fold to the right, respectively (Figure 2). Pretreatment with $32.0 \mathrm{mg} / \mathrm{kg}$; IV PEG-CCRQ CocE resulted in cocaine maintaining saline-like levels of responding, despite being available at unit doses as large $3.2 \mathrm{mg} / \mathrm{kg} / \mathrm{inj}$ (Figure 2). In addition to the dose-dependent nature of PEG-CCRQ CocE's effects on cocaine-reinforced responding, the duration of these inhibitory effects was also dependent on the dose of PEG-CCRQ CocE, with larger doses producing a longer lasting inhibition. For instance, although the doseresponse curve began to move back to the left as early as $24 \mathrm{~h}$ after PEG-CCRQ CocE, baseline-like rates of cocaine-
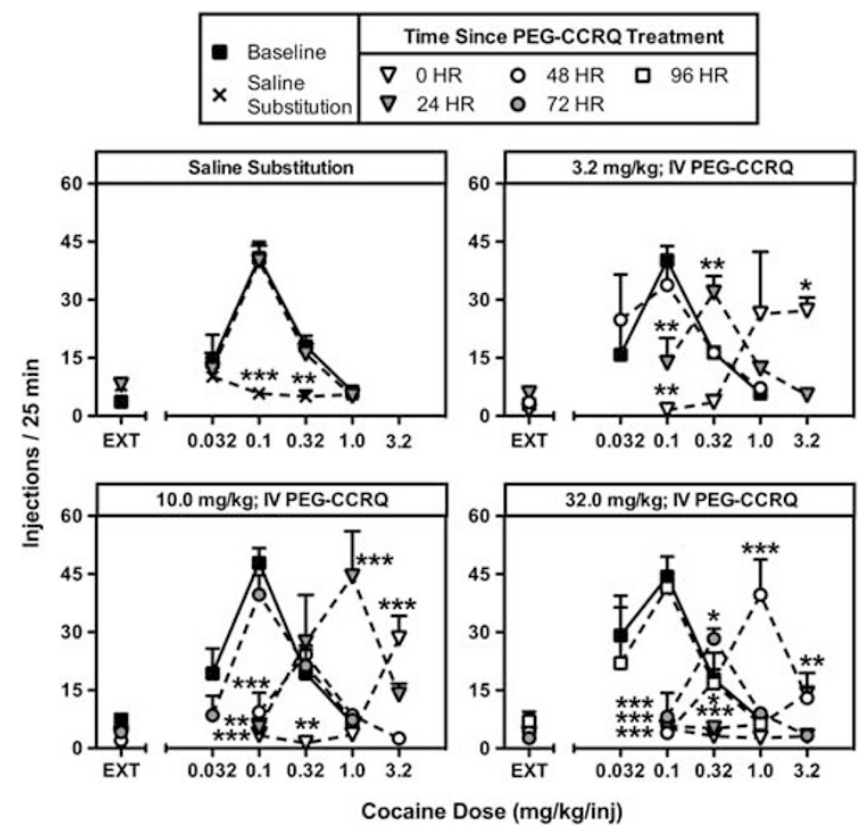

Figure 2 Time course of the effects of PEG-CCRQ CocE on FR5TO5 responding maintained by cocaine $(0-3.2 \mathrm{mg} / \mathrm{kg}$; IV) during five sequential 25 min components. Responding for cocaine (filled squares; $0.0-1.0 \mathrm{mg} / \mathrm{kg} /$ inj) during sessions immediately preceding treatment were used for baseline. Upper left panel: Responding during the substitution of saline for cocaine $(X)$, and upon reintroduction of cocaine $24 \mathrm{~h}$ later (shaded triangles). Data represent the mean \pm the standard error of the mean (SEM) number of cocaine injections $(n=6)$ earned during each 25 min component immediately after (open triangles), $24 \mathrm{~h}$ after (shaded triangles), $48 \mathrm{~h}$ after (open circles), $72 \mathrm{~h}$ after (shaded circles), and $96 \mathrm{~h}$ after (open squares) the administration of $3.2 \mathrm{mg} / \mathrm{kg}$; IV (upper right panel), $10.0 \mathrm{mg} / \mathrm{kg}$; IV (lower left panel), or $32.0 \mathrm{mg} / \mathrm{kg}$; IV PEG-CCRQ CocE (lower right panel). Points above extinction (EXT) refer to the number of completed ratios that resulted in presentation of stimuli associated with injections, but no injection. ${ }^{*} p<0.05$; $* * 0<0.01$; and ${ }^{*} * * * 0.00$ I represent points that were significantly different than baseline $(0.0-1.0$ or $0.0-3.2 \mathrm{mg} / \mathrm{kg} / \mathrm{inj}$ cocaine) as determined by two-way, repeated measures ANOVA with post hoc Bonferroni tests. 
maintained responding were not observed until $48 \mathrm{~h}$ after $3.2 \mathrm{mg} / \mathrm{kg}$ PEG-CCRQ CocE, $72 \mathrm{~h}$ after $10.0 \mathrm{mg} / \mathrm{kg}$ PEG-CCRQ CocE, and $96 \mathrm{~h}$ after pretreatment with the $32.0 \mathrm{mg} / \mathrm{kg}$ dose of PEG-CCRQ CocE.

As was observed when cocaine served as the reinforcer, substituting saline for methylphenidate resulted in a significant reduction in responding $(\mathrm{F}(1,25)=31.9$; $p<0.001)$, with significantly fewer injections earned during the third and fourth components ( $p<0.001$ for both), and baseline levels of responding recovered during the first session that methylphenidate was made available for injection (Figure 3; top panel). Unlike with cocaine,
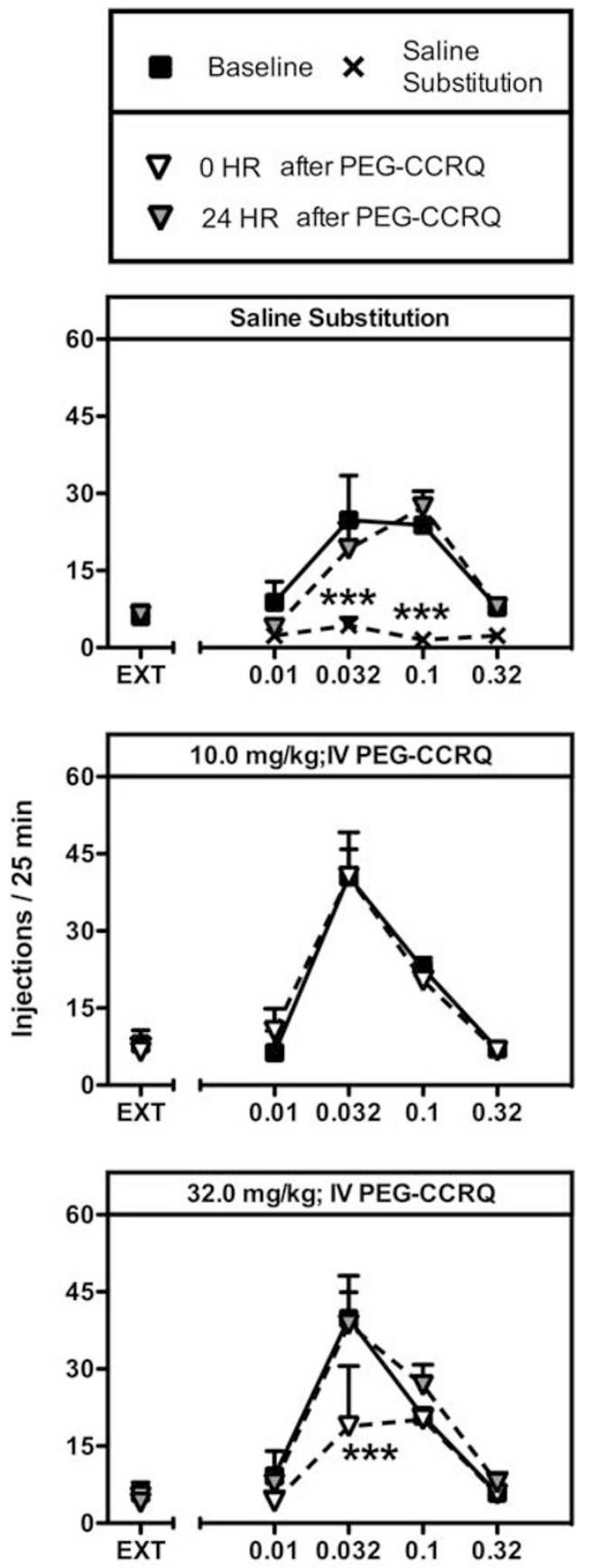

Methylphenidate Dose (mg/kg; IV) the $10-\mathrm{mg} / \mathrm{kg}$ dose of PEG-CCRQ CocE failed to alter responding maintained by methylphenidate; however, a significant disruption $(F(1,25)=9.0 ; p<0.01)$ of methylphenidate-reinforced responding was observed following the $32.0-\mathrm{mg} / \mathrm{kg}$ dose of PEG-CCRQ CocE. Despite this apparent interaction between PEG-CCRQ CocE and methylphenidate, these effects were only observed at the $0.032-\mathrm{mg} /$ $\mathrm{kg} / \mathrm{inj}$ dose of methylphenidate, and only at the 0 -h time point, with baseline levels of responding observed for all doses of methylphenidate $24 \mathrm{~h}$ later (Figure 3).

The effects of PEG-CCRQ CocE on high rates of foodreinforced responding are shown in Figure 4. Unlike the relatively restricted suppression of methylphenidate-reinforced responding, PEG-CCRQ CocE produced a slight but significant suppression of the rates of responding across the session as a whole during the 0 -h time point $(\mathrm{F}(2,50)=5.5$; $p<0.01$ ), however, post hoc tests failed to identify significant difference between the rates of responding for the PBS- and PEG-CCRQ CocE-treated groups during any of the five components. These effects were also short-lived, with baseline-like rates of responding observed $24 \mathrm{~h}$ later (data not shown). There were no significant effects of PEGCCRQ CocE on the number of food pellets earned at either the 0 - or 24-h time points. When evaluated $48 \mathrm{~h}$ after PBS treatment, cocaine produced a dose-dependent suppression of both the rates of responding $(\mathrm{F}(4,20)=9.4 ; p<0.001)$ and the total numbers of pellets earned per component $(\mathrm{F}(4,20)=5.1 ; p<0.01)$. These effects of cocaine were prevented in a dose-dependent manner by pretreatment with PEG-CCRQ CocE (rate of responding: $\mathrm{F}(2,50)=11.6$; $p<0.001$; pellets earned: $\mathrm{F}(2,50)=9.5 ; p<0.001)$, despite the fact that it was administered $48 \mathrm{~h}$ before cocaine (Figure 4; right panels).

In order to further evaluate the selectivity and duration of PEG-CCRQ CocE's effects, a group of rats were trained to discriminate cocaine $(10.0 \mathrm{mg} / \mathrm{kg}$; IP) from saline using a two-lever drug discrimination task. As shown in Figure 5, cocaine produced dose-dependent increases in the selection of the cocaine-associated lever, with $96.9 \pm 1.2 \%$ of responding occurring on the cocaine-appropriate lever following a cumulative dose of $10.0 \mathrm{mg} / \mathrm{kg}$; IP cocaine. Similar dosedependent increases in cocaine-appropriate responding were also observed when rats were pretreated with methylphenidate (maximum $88.1 \pm 7.1 \%$ ) and d-amphetamine (maximum $93.6 \pm 4.6 \%$ ), with a full generalization to

Figure 3 Time course of the effects of PEG-CCRQ CocE on FR5TO5 responding maintained by methylphenidate $(0.0-0.32 \mathrm{mg} / \mathrm{kg} / \mathrm{inj})$ during five sequential $25 \mathrm{~min}$ components. Responding for methylphenidate (filled squares; $0.0-0.32 \mathrm{mg} / \mathrm{kg} / \mathrm{inj}$ ) during sessions immediately preceding treatment were used for baseline. Upper panel: Responding during the substitution of saline for methylphenidate $(X)$, and upon reintroduction of methylphenidate $24 \mathrm{~h}$ later (shaded triangles). Data represent the mean \pm the standard error of the mean (SEM) number of methylphenidate injections $(n=6)$ earned during each 25 min component (middle panel) immediately after (open triangles), and $24 \mathrm{~h}$ after (shaded triangles) the administration of $10.0 \mathrm{mg} / \mathrm{kg}$; IV (middle panel) $32.0 \mathrm{mg} / \mathrm{kg}$; IV PEG-CCRQ CocE (lower panel). Points above extinction (EXT) refer to the number of completed ratios that resulted in presentation of stimuli associated with injections, but no injection. ${ }^{* * * *} p<0.001$ represents points that were significantly different than baseline $(0.0-32 \mathrm{mg} / \mathrm{kg} / \mathrm{inj}$ methylphenidate) as determined by two-way, repeated measures ANOVA with post hoc Bonferroni tests. 


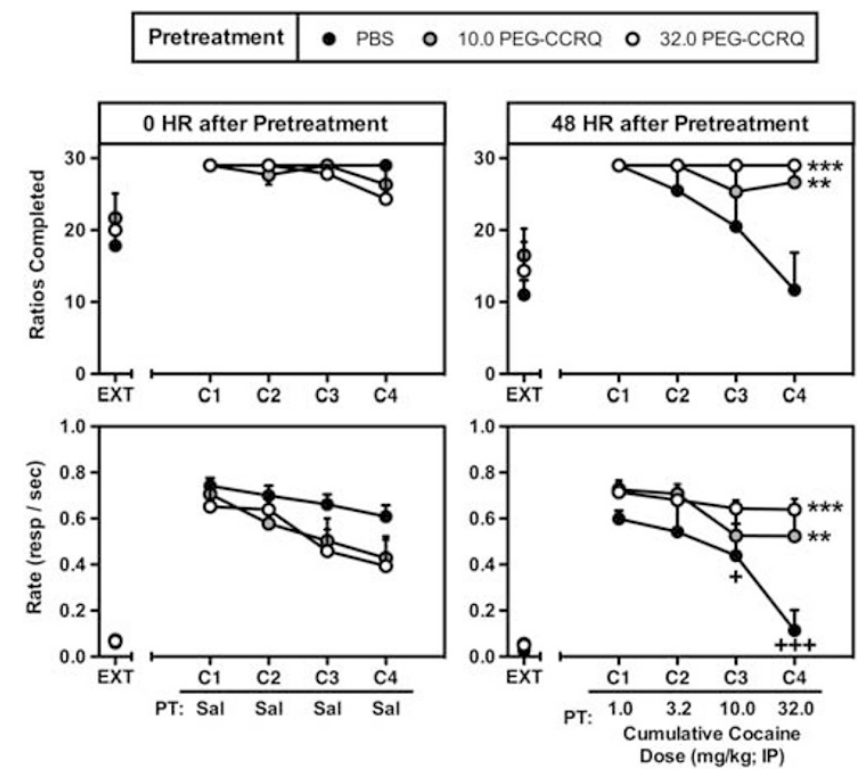

Figure 4 Effects of pretreatment with PEG-CCRQ CocE on FR5TO5 responding maintained by sucrose pellets. Number of ratios completed (upper panels) and rate of responding (responses per second; lower panels) during sessions that were preceded by the administration of PBS (filled circles), $10.0 \mathrm{mg} / \mathrm{kg}$; IV (shaded circles), or $32.0 \mathrm{mg} / \mathrm{kg}$; IV PEG-CCRQ CocE (open circles). Left panels represent responding that occurred immediately after PBS or PEG-CCRQ CocE administration, with saline injections delivered before components I through 4. Right panels represent responding during sessions that occurred $48 \mathrm{~h}$ after PBS or PEG-CCRQ CocE administration, with cumulative doses of cocaine (I.0, 3.2, I0.0, and $32.0 \mathrm{mg} / \mathrm{kg} ; \mathrm{IP}$ ) administered before components I through 4. Data represent the mean \pm the standard error of the mean (SEM) number of ratios completed or responses per second $(n=6)$ during each $25 \mathrm{~min}$ component. Points above extinction (EXT) refer responding that resulted in presentation of stimuli associated with pellet delivery, but no pellet. *** $p<0.0$ I; ${ }^{*} * * * 0<0.001 ;{ }^{+} p<0.05 ;{ }^{+++} p<0.00$ I. Significant difference in the number of ratios completed, or rate of responding between PEGCCRQ CocE-treated rats and PBS-treated rats receiving cocaine $(*)$, and PBS-treated rats not receiving cocaine (ie, $24 \mathrm{~h}$ prior) $(+)$ were determined by two-way, repeated measures ANOVA with post hoc Bonferroni tests.

the discriminative stimulus effects of cocaine at cumulative doses of 10.0 and $1.0 \mathrm{mg} / \mathrm{kg}$; IP, respectively. Unlike methylphenidate and d-amphetamine, pretreatment with ketamine failed to increase selection of the cocaineappropriate lever (maximum $3.2 \pm 1.8 \%$ ), with responding occurring almost exclusively on the saline-appropriate lever over the entire range of cumulative doses tested. The relative potencies $\left(\mathrm{ED}_{50}\right)$ of these compounds to produce cocaine-appropriate responding are shown in Table 1.

Similar to the effects of PEG-CCRQ on cocaine selfadministration, pretreatment with PEG-CCRQ CocE produced rightward shifts in the dose-response curve for cocaine-induced increases in cocaine-appropriate responding (Figure 6). Although high cumulative doses of cocaine $(180.0 \mathrm{mg} / \mathrm{kg}$; IP) were capable of producing slight increases $(>20 \%)$ in cocaine-appropriate responding during sessions immediately after pretreatment with lower doses of PEGCCRQ CocE (3.2 or $10.0 \mathrm{mg} / \mathrm{kg}$; IV), these effects were due to one rat in particular who showed higher proportions of cocaine-appropriate responding (66-78\%) following the $180.0-\mathrm{mg} / \mathrm{kg}$; IP dose of cocaine at the 0 -h time point.
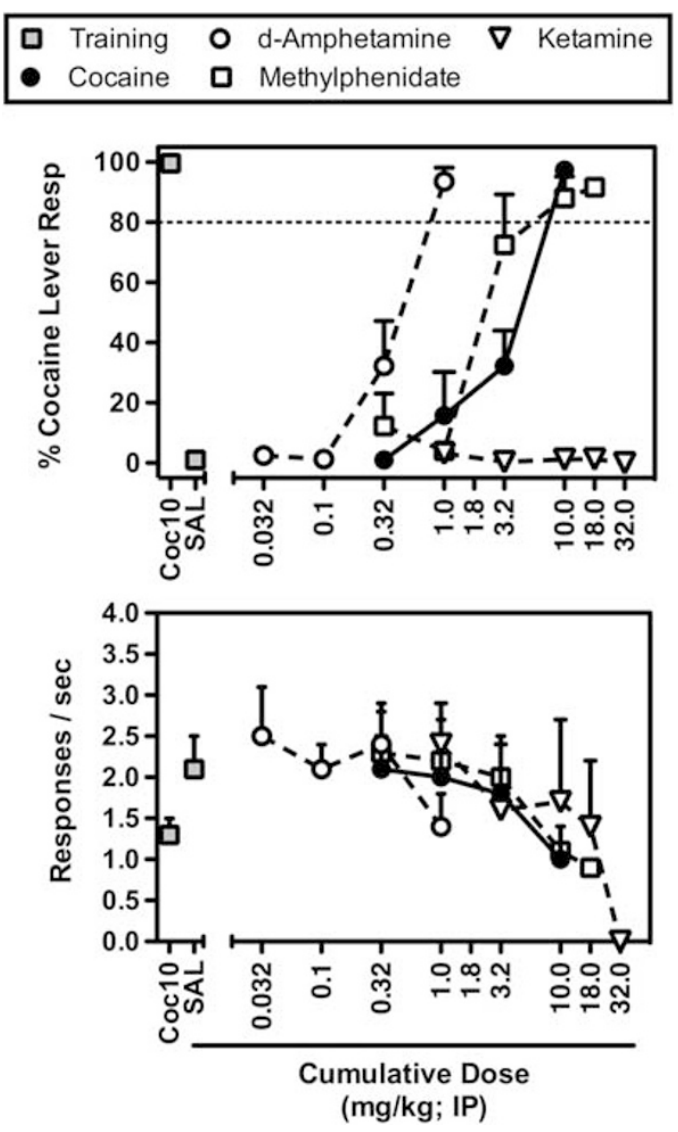

Figure 5 Effects of cocaine, methylphenidate, d-amphetamine, and ketamine in PBS-treated rats trained to discriminate $10.0 \mathrm{mg} / \mathrm{kg}$; IP cocaine from saline. Upper panel: Dose-response curves for the percent of responding that occurred on the cocaine-appropriate lever during cumulative dose substitution tests. Lower panel: Dose-response curves for the overall rate of responding during cumulative dose substitution tests. Data represent the mean \pm the standard error of the mean (SEM) for each dosing condition $(n=5)$. Shaded squares depict the effects of saline or $10.0 \mathrm{mg} / \mathrm{kg}$ cocaine on responding during training session. The dashed line at $80 \%$ represents the cutoff for full substitution.

Pretreatment with $32.0 \mathrm{mg} / \mathrm{kg}$; IV PEG-CCRQ CocE resulted in nearly exclusive responding on the saline-appropriate lever at all doses of cocaine tested, including the cumulative dose of $180.0 \mathrm{mg} / \mathrm{kg}$; IP cocaine. The duration of CocE's effects against the discriminative stimulus effects of cocaine was also dependent upon the dose of PEG-CCRQ CocE administered, with the training dose of $10.0 \mathrm{mg} / \mathrm{kg}$; IP cocaine producing $>80 \%$ cocaine-appropriate responding in the majority of rats $48 \mathrm{~h}$ after treatment with $3.2 \mathrm{mg} / \mathrm{kg}$ or $10.0 \mathrm{mg} / \mathrm{kg}$ PEG-CCRQ CocE, and $96 \mathrm{~h}$ after treatment with $32.0 \mathrm{mg} / \mathrm{kg}$ PEG-CCRQ CocE. In addition to altering cocaine's discriminative stimulus effects, pretreatment with PEG-CCRQ CocE produced a similar inhibition of cocaine's rate suppressant effects, although increasing doses of cocaine more easily surmounted these protective effects of PEG-CCRQ CocE. Nevertheless, cumulative cocaine doses as large $180.0 \mathrm{mg} / \mathrm{kg}$; IP failed to completely suppress responding at any time during the first $48 \mathrm{~h}$ after $32.0 \mathrm{mg} / \mathrm{kg}$; IV PEG-CCRQ CocE.

As shown in Figure 7, the capacity of PEG-CCRQ CocE to alter the discriminative stimulus effects of psychostimulants 
Table I Relative Potency of Substitute Drugs to Produce a Cocaine-Like Interoceptive Effect Following Pretreatment with PBS or $32.0 \mathrm{mg} / \mathrm{kg}$ PEG-CCRQ COcE

\begin{tabular}{|c|c|c|c|c|c|c|}
\hline \multirow[t]{2}{*}{ Drug } & \multicolumn{2}{|c|}{ PBS treatment } & \multicolumn{4}{|c|}{$32.0 \mathrm{mg} / \mathrm{kg}$; IV PEG-CCRQ CocE treatment } \\
\hline & $\mathrm{ED}_{50}{ }^{\mathrm{a}}$ & $(95 \% \mathrm{Cl})$ & $E D_{50}$ & $(95 \% \mathrm{Cl})$ & Dose ratio & $(95 \% \mathrm{Cl})$ \\
\hline Methylphenidate & 4.9 & $(2.2-7.9)$ & 6.1 & $(3.8-9.3)$ & 1.1 & $(0.1-2.0)$ \\
\hline d-Amphetamine & 0.6 & $(0.5-0.9)$ & 0.6 & $(0.4-0.9)$ & 1.0 & $(0.3-1.6)$ \\
\hline
\end{tabular}

Abbreviations: n.a., not applicable; n.d., not determined; n.s., slope not significant different than zero based on linear regression analysis.

${ }^{a}$ Dose that produced $50 \%$ cocaine-appropriate responding based on linear regression analysis.

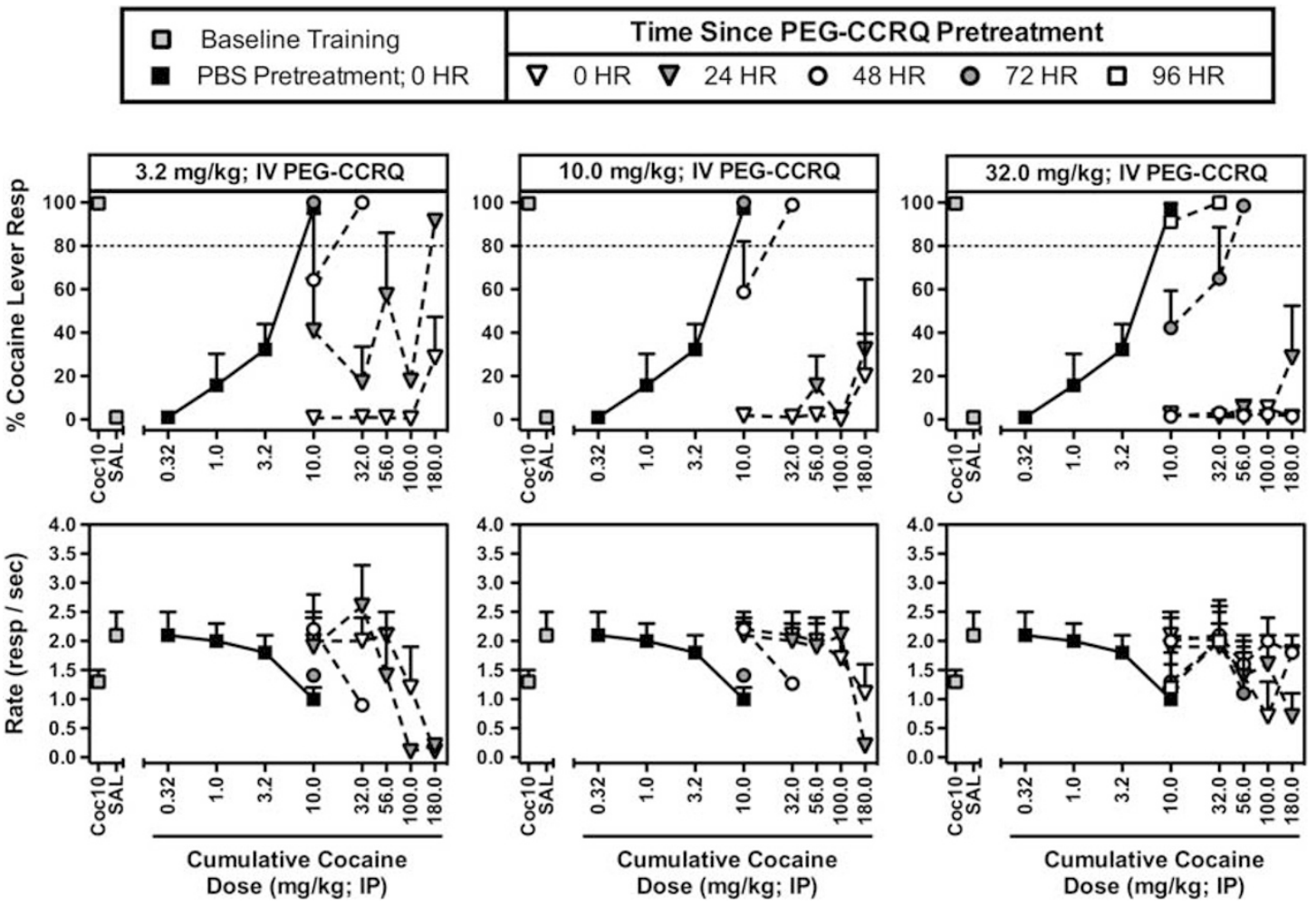

Figure 6 Time course of the effects of pretreatment with PEG-CCRQ CocE in rats trained to discriminate $10.0 \mathrm{mg} / \mathrm{kg}$ IP cocaine from saline. Effects of PEG-CCRQ (3.2, 10.0, and $32.0 \mathrm{mg} / \mathrm{kg}$; IV) on the percent of responding that occurred on the cocaine-appropriate lever (upper panels), and the overall rate of responding (lower panels) immediately after (open triangles), $24 \mathrm{~h}$ after (shaded triangles), $48 \mathrm{~h}$ after (open circles), $72 \mathrm{~h}$ after (shaded circles), and $96 \mathrm{~h}$ after (open circles) PEG-CCRQ CocE administration. Data represent the mean \pm the standard error of the mean (SEM) for each dosing condition $(n=5)$. Filled squares depict the effects of saline or $10.0 \mathrm{mg} / \mathrm{kg}$ cocaine on responding during training session. The dashed line at $80 \%$ represents the cutoff for full substitution.

was limited to cocaine, as there were no significant differences between the generalization dose-response curves obtained for methylphenidate or d-amphetamine following PBS pretreatments and those obtained $0-24 \mathrm{~h}$ after the administration of $32.0 \mathrm{mg} / \mathrm{kg}$ PEG-CCRQ CocE (Table 1). Despite this inability of PEG-CCRQ CocE to alter the discriminative stimulus effects of methylphenidate or $\mathrm{d}$-amphetamine, cumulative doses of cocaine as large as $18.0 \mathrm{mg} / \mathrm{kg}$ resulted in nearly exclusive responding on the saline-appropriate lever when it was evaluated $48 \mathrm{~h}$ after the administration of $32.0 \mathrm{mg} / \mathrm{kg}$ PEG-CCRQ CocE. Although slight increases in cocaine-appropriate responding were observed at the 10.0 and $18.0 \mathrm{mg} / \mathrm{kg}$ doses of cocaine, these effects represent increased levels of cocaine-appropriate responding in a single rat (different rat for 10.0 and $18.0 \mathrm{mg} / \mathrm{kg}$ doses), rather than a systematic increase in cocaine-appropriate responding. The $\mathrm{ED}_{50}$ values for methylphenidate, d-amphetamine, and cocaine observed following PEG-CCRQ pretreatment, as well as the fold shift from PBS produced by PEG-CCRQ CocE for each of these drugs are shown in Table 1.

\section{DISCUSSION}

We have recently described mutations resulting in a highly thermostable bacterial CocE (CCRQ CocE), as well as a PEGylated form of this enzyme (PEG-CCRQ CocE) capable 

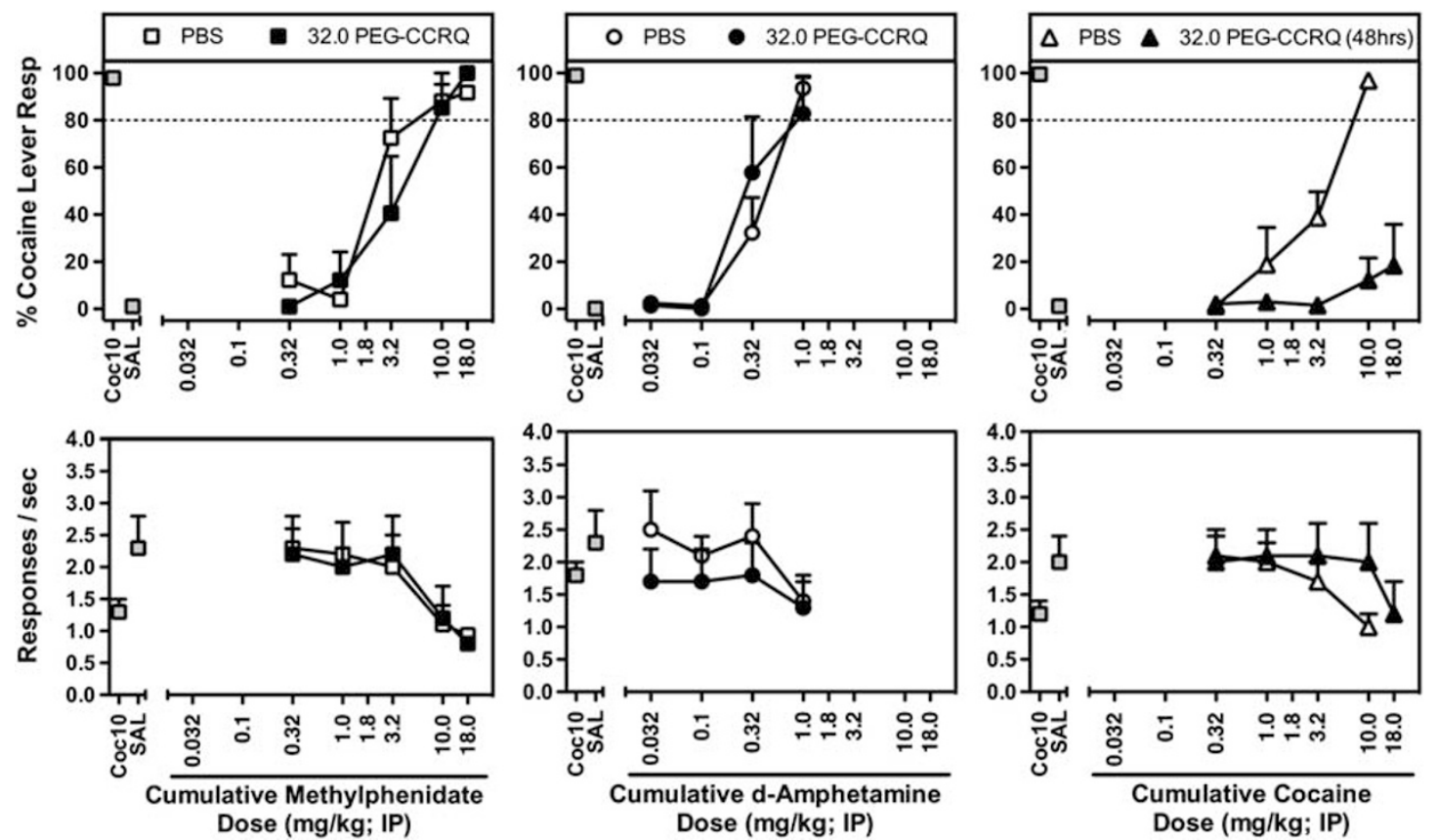

Figure 7 Effects of $32.0 \mathrm{mg} / \mathrm{kg}$; IV PEG-CCRQ CocE on the cocaine-like interoceptive effects of methylphenidate, d-amphetamine, and cocaine. Percent of responding that occurred on the cocaine-appropriate lever (upper panels), and overall rate of responding (lower panels) following the cumulative doses of methylphenidate (left; 0.32-18.0 mg/kg; IP), d-amphetamine (middle; 0.032-1.0 mg/kg; IP), and cocaine (right; 0.32-I8.0 mg/kg; IP). Dose-response curves for methylphenidate and d-amphetamine were generated 0 and $24 \mathrm{~h}$ after PEG-CCRQ CocE (counterbalanced), whereas the dose-response curve for cocaine was generated $48 \mathrm{~h}$ after PEG-CCRQ CocE. Data represent the mean \pm the standard error of the mean $(S E M)$ for each end point $(n=5)$. Filled squares depict the effects of saline or $10.0 \mathrm{mg} / \mathrm{kg}$ cocaine on responding during training session. The dashed line at $80 \%$ represents the cutoff for full substitution.

of producing a long-lasting protection against cocaine's effects in mice, rats, and rhesus monkeys (Narasimhan et al, 2011). The current studies were aimed at extending these findings by providing a thorough evaluation of the capacity of PEG-CCRQ CocE to reduce the reinforcing and discriminative stimulus effects of cocaine in rats, and there were four main findings. First, pretreatment with PEGCCRQ CocE produced a dose-dependent antagonism of IV cocaine self-administration, with a $>30$-fold rightward shift in the reinforcing effects of cocaine observed immediately after the administration of a $32.0-\mathrm{mg} / \mathrm{kg}$ dose of PEG-CCRQ CocE. Second, PEG-CCRQ CocE produced a similar dosedependent antagonism of the discriminative stimulus effects of cocaine, with a $32.0-\mathrm{mg} / \mathrm{kg}$ dose of PEG-CCRQ CocE shifting cocaine's dose-response curve at least 25-fold to the right. Third, in addition to producing greater shifts in cocaine's effects, the duration of PEG-CCRQ CocE's effects was also dose dependent, with the $32.0-\mathrm{mg} / \mathrm{kg}$ dose producing at least a three-fold shift in the discriminative stimulus and reinforcing effects of cocaine for at least $72 \mathrm{~h}$. And fourth, pretreatment with PEG-CCRQ CocE had little to no effect on the reinforcing or discriminative stimulus effect of methylphenidate and d-amphetamine, suggesting that it possesses a high degree of specificity for cocaine, and thus cocaine-related behaviors. When taken together, these studies demonstrate the capacity of PEG-CCRQ CocE to provide a long-lasting antagonism of cocaine's discriminative stimulus and reinforcing effects, and provide strong evidence to support the further development of highly efficient cocaine-hydrolyzing enzymes with extended durations of action, such as PEG-CCRQ CocE, as candidate medications for the treatment of cocaine abuse in humans.
In an extension of previous findings with DM CocE (T172R/G173Q CocE or RQ CocE; Collins et al, 2009, 2011a,b; Gao et al, 2009; Narasimhan et al, 2010), the current studies evaluated impact of introducing two cysteine residues at the dimer interface, in combination with the PEGylation of this crosslinked CocE dimer (PEGCCRQ CocE; Narasimhan et al, 2011) on duration and effectiveness of CocE to alter the behavioral effects of cocaine. Importantly, just as these changes did not alter the enzymatic activity of PEG-CCRQ CocE in vitro (Narasimhan et al, 2011), the DM (RQ) and PEG-CCRQ forms of CocE appeared to be equally effective at eliminating cocaine in vivo as both enzymes produced at least 10 -fold rightward shifts in the reinforcing effects of cocaine when comparable doses of $\sim 3 \mathrm{mg} / \mathrm{kg}$ were administered immediately before the start of cocaine self-administration sessions (Collins et al, 2009). Nevertheless, just as the prolonged duration of PEG-CCRQ CocE's protective effects differentiated it from $\mathrm{DM}$ CocE in rodent models of acute cocaine toxicity (Collins et al, 2011b; Narasimhan et al, 2011) differences between these enzymes began to emerge when PEG-CCRQ CocE was evaluated against cocaine self-administration using a multiple dose procedure that allowed for the longitudinal evaluation of an animal's sensitivity to the reinforcing effects of cocaine. Unlike the effects of $\sim 3 \mathrm{mg}$ / kg DM CocE, which had completely dissipated by $24 \mathrm{~h}$ (Collins et al, 2009), pretreatment with $3.2 \mathrm{mg} / \mathrm{kg}$ PEGCCRQ CocE produced a longer lasting change in cocaine self-administration with a three-fold rightward shift in the dose-response curve observed $24 \mathrm{~h}$ later, and baseline-like rates of responding not observed until $48 \mathrm{~h}$ after administration. Interestingly, in addition to producing larger 
rightward shifts in the reinforcing effects of cocaine (30-fold or greater), the duration of PEG-CCRQ CocE's effects also increased with dose. Similar to the increased duration of protection reported for PEG-CCRQ CocE against the lethal effects of cocaine (Narasimhan et al, 2011), larger doses of PEG-CCRQ CocE not only produced larger rightward shifts in the reinforcing effects of cocaine (30-fold or greater), but these effects were also longer lasting, with baseline-like rates of cocaine self-administration gradually returning over 72$96 \mathrm{~h}$ after the administration of higher doses of PEG-CCRQ CocE.

In contrast to the $\sim 30$-fold rightward shift in the reinforcing effects cocaine, there were no significant effects of $10.0 \mathrm{mg} / \mathrm{kg}$ PEG-CCRQ CocE on methylphenidate-reinforced responding, and only modest decreases in responding maintained by an intermediate dose of $0.032 \mathrm{mg} / \mathrm{kg} / \mathrm{inj}$ methylphenidate following pretreatment with the $32.0-\mathrm{mg} / \mathrm{kg}$ dose of PEG-CCRQ CocE. Importantly, however, unlike the prolonged inhibition observed with cocaine self-administration, the inhibition of methylphenidate-maintained responding by PEG-CCRQ CocE was shortlived, with baseline rates of responding returning within $24 \mathrm{~h}$. A similarly short-lived inhibition of the rate of food-reinforced responding was also observed following pretreatment with this high dose of PEG-CCRQ CocE, however, it is important to note that the number of food pellets earned was unaffected. Although these findings suggest that PEG-CCRQ CocE can produce a mild, nonspecific disruption of behavior when administered at high doses, these effects were relatively short-lived, and only observed with relatively high rates of responding suggesting that they resulted from the effects of the bolus administration of a large quantity of bacterially derived protein (eg, LPS-induced sickness-like behavior), rather than an enzymatic inhibition of the reinforcing effects of methylphenidate or food, per se. Nevertheless, it will be important to continue to evaluate the behavioral and pharmacologic specificity of PEG-CCRQ, and other CocEs in future studies.

Further evidence for PEG-CCRQ CocE's prolonged duration of action and high degree of pharmacologic specificity was provided by the results of studies in which rats were trained to discriminate the interoceptive effects of cocaine from saline using a multiple component, cumulative dose procedure (eg, Barrett et al, 2005; Ukai and Holtzman, 1988; Woolfolk and Holtzman, 1997), such that an animal's sensitivity to the discriminative effects of cocaine could be evaluated longitudinally after treatment with CocE. Just as with cocaine self-administration, PEG-CCRQ CocE produced a dose-dependent rightward shift in the cumulative dose-response curve for selection of the cocaine-appropriate lever. Even though slight differences in the effectiveness were observed during the initial time point following pretreatment with doses of PEG-CCRQ CocE ranging from 3.2 to $32.0 \mathrm{mg} / \mathrm{kg}$, each of these doses resulted in the majority of rats responding on the saline-appropriate lever following tests with cumulative doses of cocaine as large as $180.0 \mathrm{mg} / \mathrm{kg}$. Not only do these results suggest that PEGCCRQ CocE is capable of shifting the discriminative stimulus effects of cumulative cocaine doses at least 56-fold to the right, but they also suggests that the rats are unable to discriminate an otherwise $\mathrm{LD}_{100}$ dose of cocaine for up to $48 \mathrm{~h}$ after administration of $32.0 \mathrm{mg} / \mathrm{kg}$ PEG-CCRQ CocE.
Although the use of drug discrimination and selfadministration assays provided a consistent profile of PEG-CCRQ CocE's activity with respect to the duration and magnitude of its effects against cocaine, the evaluation of PEG-CCRQ CocE against other cocaine-like drugs in the drug discrimination assay provided much stronger evidence in support of PEG-CCRQ CocE's pharmacologic selectivity. Unlike the decrease in responding maintained by an intermediate dose of methylphenidate that was observed following pretreatment with $32.0 \mathrm{mg} / \mathrm{kg}$ PEG-CCRQ CocE in the self-administration studies, this high dose of PEGCCRQ CocE failed to alter the doses at which either methylphenidate or $\mathrm{d}$-amphetamine substituted for the discriminative stimulus effects of cocaine. Thus, even though self-administration and food reinforcement assays suggested that PEG-CCRQ CocE may produce a mild, non-selective, disruption of behavior, the absence of any non-specific effects of PEG-CCRQ CocE in the drug discrimination assay demonstrates the importance of utilizing rate-independent assays for the evaluation of pharmacologic selectivity.

Previous studies with mutant bacterial CocEs (Brim et al, 2010; Collins et al, 2009) or mutant human BChEs (Carroll et al, 2011) have demonstrated the capacity of highly efficient cocaine-specific hydrolase to inhibit the reinforcing effects of cocaine; however, in each of these studies the inhibitory effects of the enzymes were short-lived, lasting from minutes to hours. The results of the current studies with PEG-CCRQ CocE not only confirm this effect of cocaine-specific esterases, but they also provide convergent evidence that PEG-CCRQ CocE represents a significant improvement over previously described mutant bacterial and human cocaine hydrolases with respect to both the magnitude and duration of its antagonism of the reinforcing effects of cocaine. In addition to producing an initial shift of the reinforcing and discriminative stimulus effects of cocaine of $>30$-fold to the right, larger doses of PEGCCRQ CocE retained their capacity to significantly alter these abuse-related effects of cocaine for up to $72 \mathrm{~h}$ after treatment. Although some of this improvement can undoubtedly be attributed to the incorporation of the thermostabilizing cysteine residues at the dimer interface, previous reports suggest that the PEGylation of CCRQ CocE also had a significant role in increasing the in vivo duration of CCRQ CocE's action while also decreasing its immunogenic potential in rodents (Narasimhan et al, 2011). Not only are these effects consistent with the PEGylation of other biologic entities (Caliceti and Veronese, 2003), but they also suggest that optimizing the location and number of PEGylation sites may result in even longer lasting CocEs. Thus, when taken together with the findings of Narasimhan et al (2011) these findings suggest that PEGylated forms of highly efficient, cocaine-specific esterases, such as PEGCCRQ CocE may provide a safe, effective, and long-lasting therapeutic option for the treatment of cocaine abuse in humans.

\section{ACKNOWLEDGEMENTS}

Research was supported by the USPHS Grants DA 021416 and DA 023213 from NIDA. 


\section{DISCLOSURE}

GTC, DN, ARC, MEZ, JN, MK, RKS, and JHW declare that, except for income received from their primary employer, no financial support or compensation has been received from any individual or corporate entity over the past 3 years for the current research. MCK received support from SSV Therapeutics, BioXell SpA, and Purdue Pharma LP, Sepracor; RKS from Reckitt-Benckiser Pharmaceuticals; JHW from Reckitt-Benckiser Pharmaceuticals, Sepracor, and Alkermes.

\section{REFERENCES}

Baird TJ, Deng SX, Landry DW, Winger G, Woods JH (2000). Natural and artificial enzymes against cocaine. I. Monoclonal antibody $15 \mathrm{~A} 10$ and the reinforcing effects of cocaine in rats. J Pharmacol Exp Ther 295: 1127-1134.

Barrett AC, Miller JR, Dohrmann JM, Caine SB (2004). Effects of dopamine indirect agonists and selective D1-like and D2-like agonists and antagonists on cocaine self-administration and food maintained responding in rats. Neuropharmacology 47(Suppl 1): 256-273.

Barrett AC, Negus SS, Mello NK, Caine SB (2005). Effect of GABA agonists and GABA-A receptor modulators on cocaine- and food-maintained responding and cocaine discrimination in rats. J Pharmacol Exp Ther 315: 858-871.

Bresler MM, Rosser SJ, Basran A, Bruce NC (2000). Gene cloning and nucleotide sequencing and properties of a cocaine esterase from Rhodococcus sp. strain MB1. Appl Environ Microbiol 66: 904-908.

Brim RL, Nance MR, Youngstrom DW, Narasimhan D, Zhan CG, Tesmer JJ et al (2010). A thermally stable form of bacterial cocaine esterase: a potential therapeutic agent for treatment of cocaine abuse. Mol Pharmacol 77: 593-600.

Brim RL, Noon KR, Nichols J, Narasimhan D, Woods JH, Sunahara RK (2011). Evaluation of the hydrolytic activity of a long-acting mutant bacterial cocaine in the presence of commonly coadministered drugs. Drug Alcohol Depend; e-pub ahead of print 18 July 2011; doi:10.1016/j.drugalcdep.2011.06.018.

Brimijoin S, Gao Y, Anker JJ, Gliddon LA, Lafleur D, Shah R et al (2008). A cocaine hydrolase engineered from human butyrylcholinesterase selectively blocks cocaine toxicity and reinstatement of drug seeking in rats. Neuropsychopharmacology 33: 2715-2725.

Caliceti P, Veronese FM (2003). Pharmacokinetic and biodistribution properties of poly(ethylene glycol)-protein conjugates. $A d v$ Drug Deliv Rev 55: 1261-1277.

Carmona GN, Schindler CW, Greig NH, Holloway HW, Jufer RA, Cone EJ et al (2005). Intravenous butyrylcholinesterase administration and plasma and brain levels of cocaine and metabolites in rats. Eur J Pharmacol 517: 186-190.

Carrera MR, Ashley JA, Zhou B, Wirsching P, Koob GF, Janda KD (2000). Cocaine vaccines: antibody protection against relapse in a rat model. Proc Natl Acad Sci USA 97: 6202-6206.

Carroll ME, Gao Y, Brimijoin S, Anker JJ (2011). Effects of cocaine hydrolase on cocaine self-administration under a PR schedule and during extended access (escalation) in rats. Psychopharmacology (Berl) 213: 817-829.

Collins GT, Brim RL, Narasimhan D, Ko MC, Sunahara RK, Zhan CG et al (2009). Cocaine esterase prevents cocaine-induced toxicity and the ongoing intravenous self-administration of cocaine in rats. J Pharmacol Exp Ther 331: 445-455.

Collins GT, Carey KA, Narasimhan D, Nichols J, Berlin AA, Lukacs NW et al (2011a). Amelioration of the cardiovascular effects of cocaine in rhesus monkeys by a long-acting mutant form of cocaine esterase. Neuropsychopharmacology 36: 1047-1059.
Collins GT, Zaks ME, Cunningham AR, St Clair C, Nichols J, Narasimhan D et al (2011b). Effects of a long-acting mutant bacterial cocaine esterase on acute cocaine toxicity in rats. Drug Alcohol Depend; e-pub ahead of print 9 April 2011; doi:10.1016/j.drugalcdep.2011.1003.1015.

Cooper ZD, Narasimhan D, Sunahara RK, Mierzejewski P, Jutkiewicz EM, Larsen NA et al (2006). Rapid and robust protection against cocaine-induced lethality in rats by the bacterial cocaine esterase. Mol Pharmacol 70: 1885-1891.

Dackis C, O'Brien C (2003). Glutamatergic agents for cocaine dependence. Ann NY Acad Sci 1003: 328-345.

Fox BS, Kantak KM, Edwards MA, Black KM, Bollinger BK, Botka AJ et al (1996). Efficacy of a therapeutic cocaine vaccine in rodent models. Nat Med 2: 1129-1132.

Gao D, Narasimhan DL, Macdonald J, Brim R, Ko MC, Landry DW et al (2009). Thermostable variants of cocaine esterase for long-time protection against cocaine toxicity. Mol Pharmacol 75: 318-323.

Grabowski J, Shearer J, Merrill J, Negus SS (2004). Agonist-like, replacement pharmacotherapy for stimulant abuse and dependence. Addict Behav 29: 1439-1464.

Haney M, Gunderson EW, Jiang H, Collins ED, Foltin RW (2010). Cocaine-specific antibodies blunt the subjective effects of smoked cocaine in humans. Biol Psychiatry 67: 59-65.

Hiranita T, Soto PL, Newman AH, Katz JL (2009). Assessment of reinforcing effects of benztropine analogs and their effects on cocaine self-administration in rats: comparisons with monoamine uptake inhibitors. J Pharmacol Exp Ther 329: 677-686.

Jutkiewicz EM, Baladi MG, Cooper ZD, Narasimhan D, Sunahara RK, Woods JH (2009). A bacterial cocaine esterase protects against cocaine-induced epileptogenic activity and lethality. Ann Emerg Med 54: 409-420.

Kantak KM, Collins SL, Lipman EG, Bond J, Giovanoni K, Fox BS (2000). Evaluation of anti-cocaine antibodies and a cocaine vaccine in a rat self-administration model. Psychopharmacology (Berl) 148: 251-262.

Ko MC, Bowen LD, Narasimhan D, Berlin AA, Lukacs NW, Sunahara RK et al (2007). Cocaine esterase: interactions with cocaine and immune responses in mice. J Pharmacol Exp Ther 320: 926-933.

Ko MC, Narasimhan D, Berlin AA, Lukacs NW, Sunahara RK, Woods JH (2009). Effects of cocaine esterase following its repeated administration with cocaine in mice. Drug Alcohol Depend 101: 202-209.

Landry DW, Yang GX (1997). Anti-cocaine catalytic antibodies - a novel approach to the problem of addiction. J Addict Dis 16: $1-17$.

Landry DW, Zhao K, Yang GX, Glickman M, Georgiadis TM (1993). Antibody-catalyzed degradation of cocaine. Science 259: 1899-1901.

Larsen NA, Turner JM, Stevens J, Rosser SJ, Basran A, Lerner RA et al (2002). Crystal structure of a bacterial cocaine esterase. Nat Struct Biol 9: 17-21.

Lynch TJ, Mattes CE, Singh A, Bradley RM, Brady RO, Dretchen KL (1997). Cocaine detoxification by human plasma butyrylcholinesterase. Toxicol Appl Pharmacol 145: 363-371.

Martell BA, Mitchell E, Poling J, Gonsai K, Kosten TR (2005). Vaccine pharmacotherapy for the treatment of cocaine dependence. Biol Psychiatry 58: 158-164.

Mello NK (1990). Preclinical evaluation of the effects of buprenorphine, naltrexone and desipramine on cocaine selfadministration. NIDA Res Monogr 105: 189-195.

Mello NK, Bowen CA, Mendelson JH (2002). Comparison of plasma cocaine levels during a 'binge' pattern of cocaine administration in male and female rhesus monkeys. Psychopharmacology (Berl) 164: 19-26. 
Mendelson JH, Mello NK, Sholar MB, Siegel AJ, Kaufman MJ, Levin JM et al (1999). Cocaine pharmacokinetics in men and in women during the follicular and luteal phases of the menstrual cycle. Neuropsychopharmacology 21: 294-303.

Mets B, Winger G, Cabrera C, Seo S, Jamdar S, Yang G et al (1998). A catalytic antibody against cocaine prevents cocaine's reinforcing and toxic effects in rats. Proc Natl Acad Sci USA 95: 10176-10181.

Narasimhan D, Collins GT, Nance MR, Nichols J, Edwald E, Chan J et al (2011). Subunit stabilization and PEGylation of cocaine esterase improves in vivo residence time. Mol Pharmacol; e-pub ahead of print 2 September 2011.

Narasimhan D, Nance MR, Gao D, Ko MC, Macdonald J, Tamburi $P$ et al (2010). Structural analysis of thermostabilizing mutations of cocaine esterase. Protein Eng Des Sel 23: 537-547.

Pan Y, Gao D, Yang W, Cho H, Yang G, Tai HH et al (2005). Computational redesign of human butyrylcholinesterase for anticocaine medication. Proc Natl Acad Sci USA 102: 16656-16661.

Platt DM, Rowlett JK, Spealman RD (2002). Behavioral effects of cocaine and dopaminergic strategies for preclinical medication development. Psychopharmacology (Berl) 163: 265-282.

Roberts DC, Brebner K (2000). GABA modulation of cocaine selfadministration. Ann NY Acad Sci 909: 145-158.

Tanda G, Newman AH, Katz JL (2009). Discovery of drugs to treat cocaine dependence: behavioral and neurochemical effects of atypical dopamine transport inhibitors. Adv Pharmacol 57: 253-289.
Turner JM, Larsen NA, Basran A, Barbas III CF, Bruce NC, Wilson IA et al (2002). Biochemical characterization and structural analysis of a highly proficient cocaine esterase. Biochemistry 41: 12297-12307.

Ukai M, Holtzman SG (1988). Restricted feeding does not modify discriminative stimulus effects of morphine in the rat. Pharmacol Biochem Behav 29: 201-203.

UNODC (2010). World Drug Report 2010.

Vocci FJ, Acri J, Elkashef A (2005). Medication development for addictive disorders: the state of the science. Am J Psychiatry 162: 1432-1440.

Wood SK, Narasimhan D, Cooper Z, Sunahara RK, Woods JH (2010). Prevention and reversal by cocaine esterase of cocaineinduced cardiovascular effects in rats. Drug Alcohol Depend 106: 219-229.

Woolfolk DR, Holtzman SG (1997). mu-, delta- and kappa-opioid receptor agonists do not alter the discriminative stimulus effects of cocaine or d-amphetamine in rats. Drug Alcohol Depend 48: 209-220.

Xue L, Ko MC, Tong M, Yang W, Hou S, Fang L et al (2010). Design, preparation and characterization of high-activity mutants of human butyrylcholinesterase specific for detoxification of cocaine. Mol Pharmacol 79: 290-297.

Zhan CG, Zheng F, Landry DW (2003). Fundamental reaction mechanism for cocaine hydrolysis in human butyrylcholinesterase. J Am Chem Soc 125: 2462-2474.

Zheng F, Yang W, Ko MC, Liu J, Cho H, Gao D et al (2008). Most efficient cocaine hydrolase designed by virtual screening of transition states. J Am Chem Soc 130: 12148-12155. 